\title{
Yttrium-doped and Conductive Polymer-Coated High Nickel Layered Cathode Material with Enhanced Structural Stability
}

\author{
Ji-Woong Shin, Seon-Jin Lee, Yun-Chae Nam and Jong-Tae Son* \\ Department of Nano-Polymer Science \& Engineering Korea National University of Transportation, 50, Daehak-ro, Dae- \\ sowon-myeon, Chungju-si, Chungcheongbuk-do, Korea
}

\begin{abstract}
In this study, high nickel layered $\mathrm{LiNi}_{0.8} \mathrm{Co}_{0.1} \mathrm{Mn}_{0.1} \mathrm{O}_{2}$ cathode materials for lithium-ion batteries were modified by yttrium doping and poly(3,4-ethylenedioxythiophene):poly(styrene sulfonate) (PEDOT:PSS) coating. The effects of yttrium doping and PEDOT:PSS coating on the structural and electrochemical properties of the $\mathrm{LiNi}_{0.8} \mathrm{Co}_{0.1} \mathrm{Mn}_{0.1} \mathrm{O}_{2}$ cathode material were investigated and compared. The substitution of nickel with an electrochemically inert yttrium was confirmed to be successful in stabilizing the layered structure framework. Moreover, coating the surfaces of the $\mathrm{LiNi}_{0.8} \mathrm{Co}_{0.1} \mathrm{Mn}_{0.1} \mathrm{O}_{2}$ particles with a conductive polymer, PEDOT:PSS, improved the capacity retention, thermal stability, and impedance of the cathode material by increasing its ionic and electric conductivities.
\end{abstract}

Keywords : Yttrium Doping, Conductive Polymer Coating, Cathode Material

Received : 18 Septebmer 2020, Accepted : 26 January 2021

\section{Introduction}

Layered metal oxide, $\mathrm{LiCoO}_{2}$, is the most attractive cathode material for rechargeable lithium-ion batteries because of its stable electrochemical cycling and ease of production [1,2]. However, the high cost and low discharge capacity of cobalt motivated the study of possible alternatives. High nickel cathode materials have been proposed as an alternative to $\mathrm{LiCoO}_{2}$ owing to their relatively higher discharge capacity and lower material cost [3]. However, they have severe disadvantages such as poor cycle performance, low rate capability, and thermal instability in organic electrolytes $[4,5]$. Therefore, intensive research has been performed on the Ni-rich cathode materials, which also possess the advantages of $\mathrm{LiCoO}_{2}$. One approach to improve the electrochemical performance is to substitute nickel cobalt manganese oxides partially with non-transition metals, which may stabilize the layered structure without

*E-mail address: jt1234@ut.ac.kr

DOI: https://doi.org/10.33961/jecst.2020.01445

This is an open-access article distributed under the terms of the Creative Commons Attribution Non-Commercial License (http://creativecommons.org/licenses/by-nc/4.0) which permits unrestricted non-commercial use, distribution, and reproduction in any medium, provided the original work is properly cited. participating in the redox processes and prevent unwanted reactions between cathode and electrolyte. So far, elements such as Fe and $\mathrm{Mg}$ have been reported for the partial substitution of $\mathrm{Ni}$ to reduce cation mixing and improve the rate capability of cathode materials $[6,7]$. Hence, substitution of $\mathrm{Ni}$ in $\mathrm{Ni}$ based oxides may be a good method to modify the structural and electrochemical performances of these materials. In this study, yttrium ion was selected as a doping element because of its larger binding energy with oxygen than nickel ion, thereby stabilizing the lattice structure by preventing oxygen loss in the delithiated state $[8,9]$. In addition, extensive studies have been carried out to coat the surface of cathode materials with conductive polymers. The surface modification of cathode materials with a conductive polymer is quite beneficial with respect to the delivery of the original capacity without reduction in the amount of electrochemically active elements present in cathode materials [10]. Among various conductive polymers, poly $(3,4$-ethylenedioxythiophene):poly(styrene sulfonate) (PEDOT:PSS) is one of the promising coating materials owing to its high electronic conductivity and good electrochemical stability [11-13]. In this study, we report the effects of doping with yttrium and coating with PEDOT:PSS 
on the structural and electrochemical properties of the $\mathrm{LiNi}_{0.8} \mathrm{Co}_{0.1} \mathrm{Mn}_{0.1} \mathrm{O}_{2}$ system. The changes in the electrochemical characteristics of the material upon doping and coating are explained with the results of our $\mathrm{dQ} / \mathrm{dV}$ plot and electrochemical impedance test. The safety characteristics of the doped and coated materials in their fully charged states were studied using differential scanning calorimetry (DSC).

\section{Experiments}

$\mathrm{Ni}_{0.8} \mathrm{Co}_{0.1} \mathrm{Mn}_{0.1}(\mathrm{OH})_{2}$ precursor was prepared by the co-precipitation method using stoichiometric amounts of $\mathrm{NiSO}_{4} \cdot 6 \mathrm{H}_{2} \mathrm{O}(\mathrm{SAMCHUN}), \mathrm{CoSO}_{4} \cdot 7 \mathrm{H}_{2} \mathrm{O}(\mathrm{SAM}-$ CHUN, 98\%), and $\mathrm{MnSO}_{4} \cdot \mathrm{H}_{2} \mathrm{O}$ (SAMCHUN, 98\%). First, a stoichiometric amount of metal solution at a concentration of $1 \mathrm{~mol} \mathrm{~L}^{-1}$ was pumped into a continuously stirred tank reactor (4 L) under a $\mathrm{N}_{2}$ atmosphere. Simultaneously, $2 \mathrm{~mol} \mathrm{~L}^{-1}$ of $\mathrm{NaOH}$ solution (SAMCHUN) and a desired amount of $\mathrm{NH}_{4} \mathrm{OH}$ solution (SAMCHUN) as a chelating agent were also separately pumped into the reactor. The $\mathrm{pH}$ of the entire reaction process was maintained between 11.5 and 12.0.

The obtained $\mathrm{Ni}_{0.8} \mathrm{Co}_{0.1} \mathrm{Mn}_{0.1}(\mathrm{OH})_{2}$ precursor was thoroughly mixed, ball-milled for at least $24 \mathrm{~h}$ with an appropriate amount of $\mathrm{LiOH} \cdot \mathrm{H}_{2} \mathrm{O}$ (Aldrich, 98\%) and $\mathrm{Y}_{2} \mathrm{O}_{3}$ (Aldrich, $\left.<50 \mathrm{~nm}\right)$ powder $(0.025 \mathrm{~mol} \%$ ratio in total cation), and calcined at $750^{\circ} \mathrm{C}$ for $10 \mathrm{~h}$ in an $\mathrm{O}_{2}$ atmosphere. However, a slightly excess stoichiometry of lithium (1.09) was used to compensate for any loss of the metal, which might have occurred during firing at high temperature.

PEDOT:PSS (Aldrich) was dispersed in ethanol at a concentration of $1 \mathrm{wt} \%$. The yttrium-doped $\mathrm{LiNi}_{0.8} \mathrm{Co}_{0.1} \mathrm{Mn}_{0.1} \mathrm{O}_{2}$ powders were mixed into the polymer solution, and the mixture was stirred at $60^{\circ} \mathrm{C}$ for $12 \mathrm{~h}$ to induce surface coating of the yttrium- doped $\mathrm{LiNi}_{0.8} \mathrm{Co}_{0.1} \mathrm{Mn}_{0.1} \mathrm{O}_{2}$ powders. After filtering the mixed solution and drying under vacuum at $120^{\circ} \mathrm{C}$ for $24 \mathrm{~h}$, surface-coated $\mathrm{LiNi}_{0.8} \mathrm{Co}_{0.1} \mathrm{Mn}_{0.1} \mathrm{O}_{2}$ powders were obtained.

$X$-ray diffraction (XRD) patterns were obtained using an X-ray diffractometer in the $2 \theta$ range from 10 to $70^{\circ}$ and with monochromatic $\mathrm{Cu}-\mathrm{K} \alpha$ radiation $(\lambda=$ $1.5406 \AA$ ). Samples were investigated using scanning electron microscopy (SEM, QUANTA 300, JEOL) analysis before and after doping. CR2032 type coin cells were assembled in a glove box using the above cathode film, lithium, a porous polyethylene film, and a $1 \mathrm{M} \mathrm{LiPF}_{6}$ solution in ethylene carbonate (EC)/ diethyl carbonate (DEC) $(1: 1 \mathrm{vol} / \mathrm{vol})$. The lithium metal foil was used as the counter and reference electrode. The assembly was measured in an argon-filled glove box. The charge-discharge curves were measured at voltages ranging from 3.0 to $4.5 \mathrm{~V}$. Impedance spectroscopy was carried out at room temperature using frequencies ranging from $0.01 \mathrm{~Hz}$ to $0.1 \mathrm{MHz}$ at an alternating-current amplitude of $10 \mathrm{mV}$. Nyquist plots (Z'vs -Z') were drawn and analyzed using $Z$ plot and $Z$ view software.

\section{Results and Discussion}

Fig. 1 shows the SEM images of the bare, Y-doped, and Y-PEDOT:PSS cathode materials. It is evident that the particles adopted a spherical morphology in the secondary particles, and the estimated particle diameter was about 4-5 $\mu \mathrm{m}$. Bare and Y-doped cathode materials represented secondary particles of a similar shape; however, the PEDOT:PSS-coated cathode material showed dense secondary particles.

Fig. 2 shows the XRD patterns of the bare, Ydoped, and Y-PEDOT:PSS cathode materials. All peaks corresponded to a layered $\alpha-\mathrm{NaFeO}_{2}$ structure

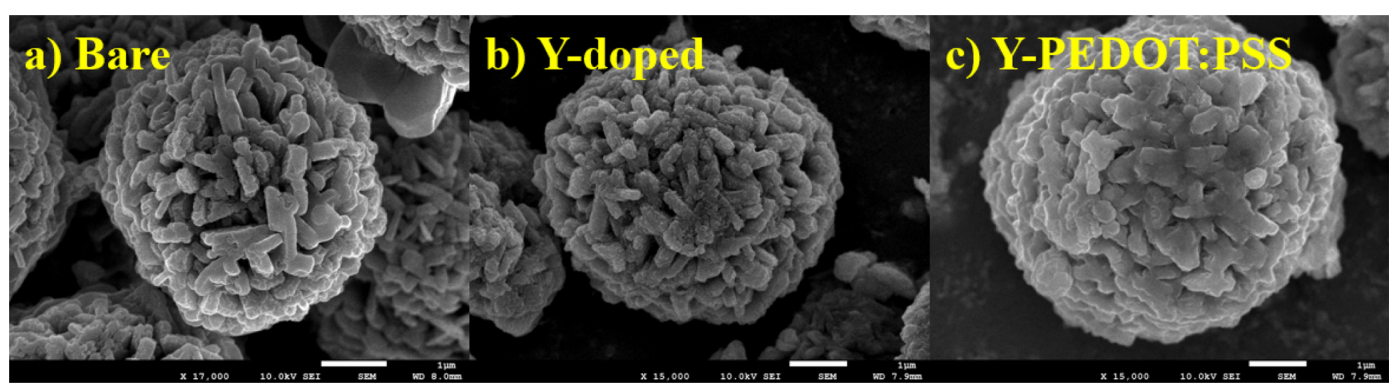

Fig. 1. SEM images of (a) bare, (b) Y-doped, and (c) Y-PEDOT:PSS cathode materials. 


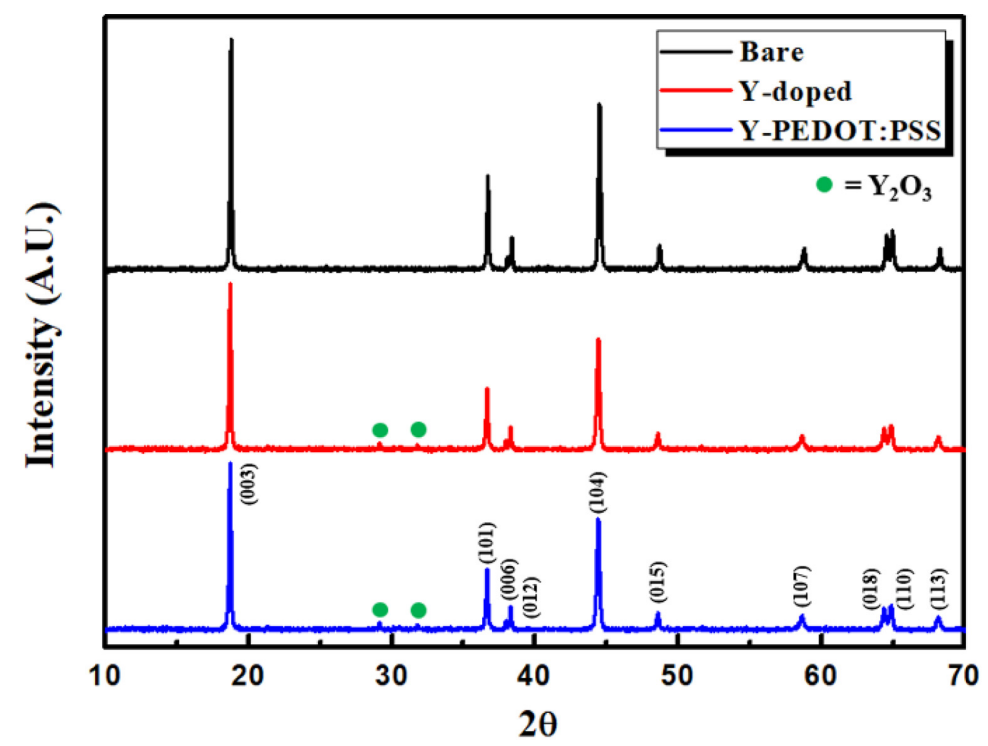

\begin{tabular}{|c|c|c|c|c|c|}
\hline & $\mathbf{a}(\boldsymbol{\AA})$ & $\mathbf{c ~}(\boldsymbol{\AA})$ & $\mathbf{V 3}$ & $\mathbf{I}(\mathbf{0 0 3}) / \mathbf{I}(\mathbf{1 0 4})$ & $\mathbf{R}$-factor \\
\hline Bare & $\begin{array}{c}2.8692 \\
( \pm 0.0002)\end{array}$ & $\begin{array}{c}14.1750 \\
( \pm 0.0008)\end{array}$ & $\begin{array}{c}101.0618 \\
( \pm 0.01)\end{array}$ & 1.3923 & 0.4583 \\
\hline Y-doped & $\begin{array}{c}2.8685 \\
( \pm 0.0001)\end{array}$ & $\begin{array}{c}14.1782 \\
( \pm 0.0005)\end{array}$ & $\begin{array}{c}101.0622 \\
( \pm 0.01)\end{array}$ & 1.5452 & 0.4439 \\
\hline Y-PEDOT:PSS & $\begin{array}{c}2.8684 \\
( \pm 0.0001)\end{array}$ & $\begin{array}{c}14.1784 \\
( \pm 0.0003)\end{array}$ & $\begin{array}{c}101.0623 \\
( \pm 0.01)\end{array}$ & 1.5450 & 0.4442 \\
\hline
\end{tabular}

Fig. 2. XRD pattern of bare, Y-doped, and Y-PEDOT:PSS cathode materials.

of space group $R-3 \mathrm{~m}$. However, some low intensity bands appeared after doping $\mathrm{Y}^{3+}$ ions at a high level, which is attributed to $\mathrm{Y}_{2} \mathrm{O}_{3}$ phase formation [14]. The lattice parameters of the Y-doped cathode material were larger compared to that of the bare cathode material. This indicates that the $\mathrm{Y}^{3+}$ ion entered into the crystal lattice. The increase in the lattice constant $c$ was attributed to the larger ionic diameter of $\mathrm{Y}^{3+}$ $(0.90 \AA)$ than that of $\mathrm{Ni}^{2+}(0.69 \AA)$ [15]. The table shows the lattice constants and ratio of the intensities of the (003) peak and (104) peak (I(003)/I(104)) to evaluate the crystal structure differences after doping. In this study, the $\mathrm{I}(003) / \mathrm{I}(104)$ ratio after $\mathrm{Y}^{3+}$ doping increases, which implies that $\mathrm{Ni}$ ions in the lithium layer were depressed by yttrium substitution. The Rfactor of the bare, Y-doped and Y-PEDOT:PSS cathode materials were $0.4583,0.4439$ and 0.4442 , respectively, indicating that the Y-doped and YPEDOT:PSS cathode materials had good hexagonal ordering [16]. However, the values of I(003)/I(104) and R-factor hardly changed in the PEDOT:PSS- coated cathode material. This means that PEDOT:PSS coating does not affect the lattice.

The charge-discharge curves of the bare, Y-doped, and Y-PEDOT:PSS cells were evaluated at a current density of $17 \mathrm{~mA} / \mathrm{g}$ in the voltage range of $3.0-4.5 \mathrm{~V}$ as shown in Fig. 3. The discharge capacity of the Ydoped cathode material was slightly decreased. The electrochemically inactive $\mathrm{Y}^{3+}$ ions substitute the nickel sites; hence, the discharge capacity is reduced. However, the crystal structure is stable and improved cycle performances can be expected. To verify Liextraction-induced phase transitions during cycling, $\mathrm{dQ} / \mathrm{dV}$ profiles of both the cathode materials were obtained by differentiating the charge-discharge curves. The $\mathrm{M} \leftrightarrow \mathrm{H} 2$ and $\mathrm{H} 2 \leftrightarrow \mathrm{H} 3$ phase transition can be attributed to the abrupt lattice shrinkage/ expansion. It can be seen that the Y-doped cathode material has the phase transition suppressed by the stabilization of the crystal structure. However, the PEDOT:PSS-coated cathode material shows a graph similar to the Y-doped cathode material. This means 

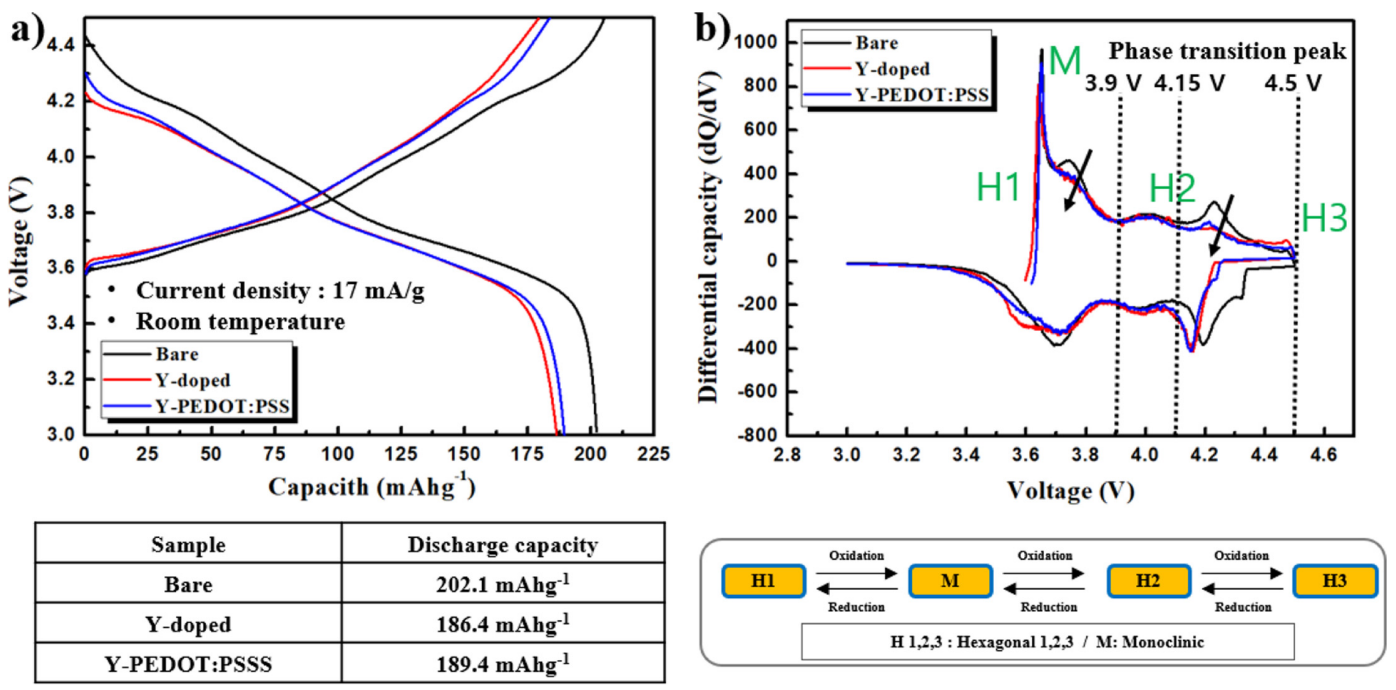

Fig. 3. (a) Initial charge-discharge and (b) differential capacity (dQ/dV) curves of bare, Y-doped, and Y-PEDOT:PSS cathode materials.
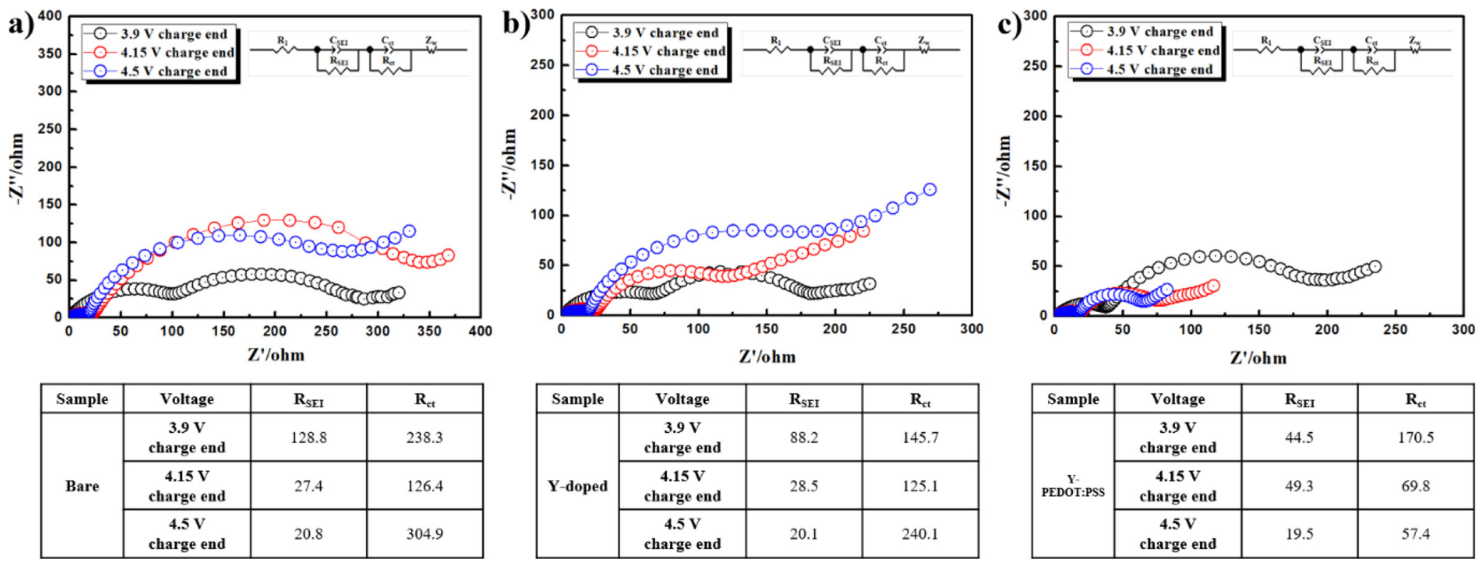

\begin{tabular}{|c|c|c|c|}
\hline Sample & Voltage & $\mathbf{R}_{\text {SEI }}$ & $\mathbf{R}_{\mathrm{et}}$ \\
\hline \multirow{4}{*}{$\begin{array}{c}\text { Y.: } \\
\text { PEDOT:PSS }\end{array}$} & $\begin{array}{c}\mathbf{3 . 9} \mathbf{~ V} \\
\text { charge end }\end{array}$ & 44.5 & 170.5 \\
\cline { 2 - 4 } & $\begin{array}{c}\mathbf{4 . 1 5} \mathbf{V} \\
\text { charge end }\end{array}$ & 49.3 & 69.8 \\
\cline { 2 - 4 } & $\begin{array}{c}\mathbf{4 . 5} \mathbf{V} \\
\text { charge end }\end{array}$ & 19.5 & 57.4 \\
\hline
\end{tabular}

Fig. 4. Impedance test of (a) bare, (b) Y-doped, and (c) Y-PEDOT:PSS cathode materials.

that the coating of the conductive polymer does not affect the crystal structure.

Impedance analysis was performed at $3.9,4.15$, and $4.5 \mathrm{~V}$, i.e., the voltages at which phase transition occurred during the charging process in the $\mathrm{dQ} / \mathrm{dV}$ plot. Fig. 5 shows the AC impedance spectrum and Nyquist plot to better demonstrate the reasons for the improved electrochemical performance of the halfcell. The electrode data show the $\mathrm{R}_{\mathrm{SEI}}$ and $\mathrm{R}_{\mathrm{ct}}$, indicating solid electrolyte interphase resistance $\left(\mathrm{R}_{\mathrm{SEI}}\right)$ and charge transfer resistance $\left(\mathrm{R}_{\mathrm{ct}}\right)$. The semicircle at low frequencies reflects charge-transfer resistance and interfacial capacitance between the electrodes and electrolyte and the semicircle at high frequencies reflects film resistance [17]. We can obtain some information of the cathode surface during cycling from the first semicircle, which reflects film resistance. The doped and coated cathode material exhibits similar resistance over all voltage ranges compared to bare cathode material. This is because the polymer is porous and evenly coated on the surface of the positive electrode material, so that the migration of $\mathrm{Li}$ ions is not disturbed. It is clear from the Fig. 5 that a pronounced difference appears at the 

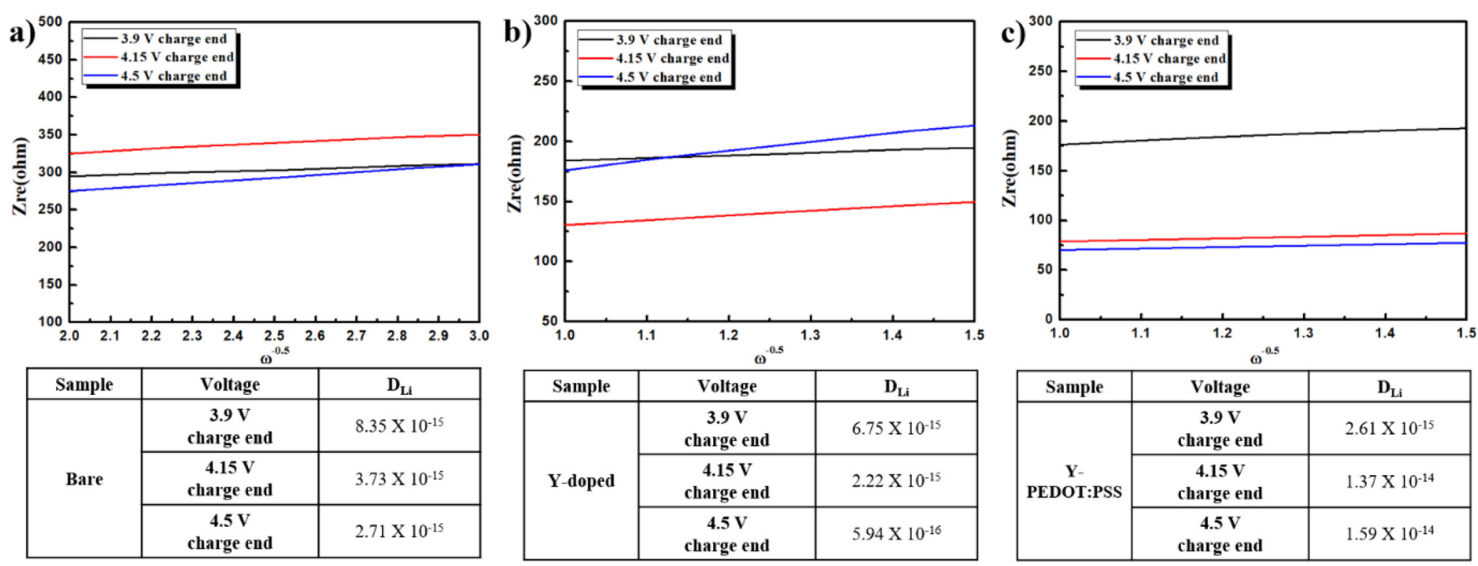

Fig. 5. Graph of $Z_{\text {re }}$ plotted against $\omega^{-0.5}$ in a low frequency region for (a) bare, (b) Y-doped, and (c) Y-PEDOT:PSS cathode materials.
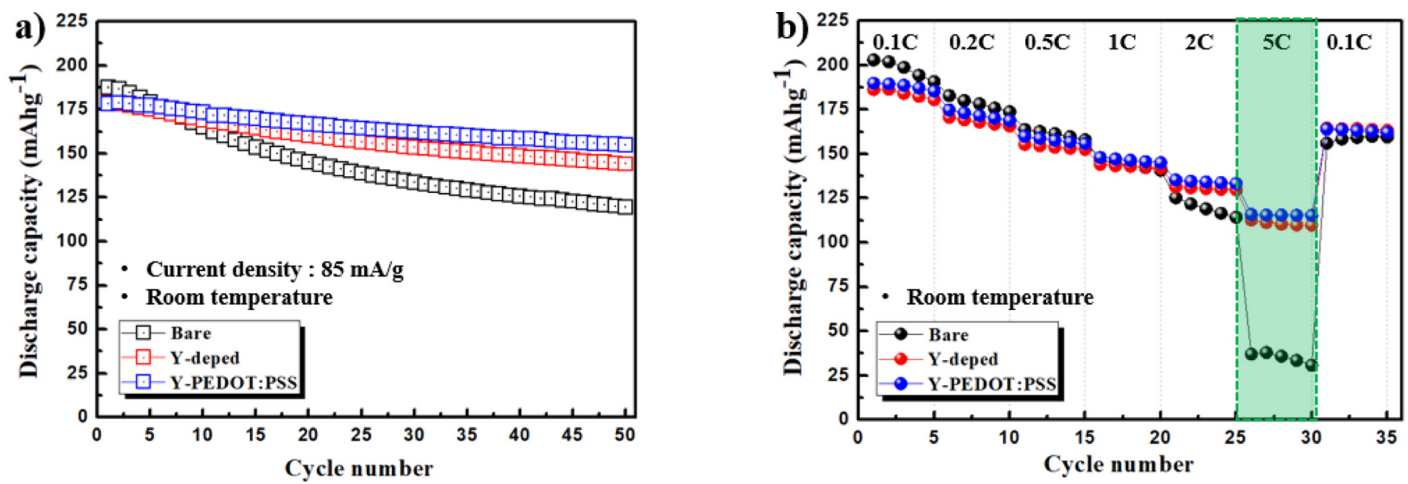

\begin{tabular}{|c|c|c|c|}
\hline Sample & $\begin{array}{c}1^{\text {st }} \text { Discharge } \\
\text { capacity }\end{array}$ & $\begin{array}{c}50^{\text {st }} \text { Discharge } \\
\text { capacity }\end{array}$ & $\begin{array}{c}\text { Cycle } \\
\text { retention }\end{array}$ \\
\hline Bare & $187.6 \mathrm{mAhg}^{-1}$ & $119.5 \mathrm{mAhg}^{-1}$ & $63.7 \%$ \\
\hline Y-doped & $178.7 \mathrm{mAhg}^{-1}$ & $144.2 \mathrm{mAhg}^{-1}$ & $80.7 \%$ \\
\hline Y-PEDOT:PSSS & $178.9 \mathrm{mAhg}^{-1}$ & $155.1 \mathrm{mAhg}^{-1}$ & $86.7 \%$ \\
\hline
\end{tabular}

\begin{tabular}{|c|c|c|c|c|c|c|c|}
\hline Sample & $0.1 \mathrm{C}$ & $0.2 \mathrm{C}$ & $\mathbf{0 . 5 C}$ & 1C & 2C & 5C & $\mathbf{0 . 1 C}$ \\
\hline Bare & $100 \%$ & $90.1 \%$ & $81.5 \%$ & $72.6 \%$ & $60.4 \%$ & $17.7 \%$ & $80.2 \%$ \\
\hline Y-doped & $100 \%$ & $91.3 \%$ & $83.6 \%$ & $77.7 \%$ & $70.9 \%$ & $60.2 \%$ & $89.2 \%$ \\
\hline Y-PEDOT:PSSS & $100 \%$ & $91.3 \%$ & $83.9 \%$ & $77.8 \%$ & $71.3 \%$ & $61.4 \%$ & $86.7 \%$ \\
\hline
\end{tabular}

Fig. 6. (a) Cycle performance and (b) rate capability of bare, Y-doped, and Y-PEDOT:PSS cathode materials.

second semicircle $\left(\mathrm{R}_{\mathrm{ct}}\right)$. Doped and coated cathode materials exhibit low $\mathrm{R}_{\mathrm{ct}}$ in all voltage ranges. This reduced $\mathrm{R}_{\mathrm{ct}}$ is suggested to be due to the high electrical conductivity of PEDOT:PSS, and the migration path of Li layer widened by Y doping.

EIS can be used to calculate the lithium diffusion coefficient $\left(\mathrm{D}_{\mathrm{Li}}\right)$ using the following equations: where $R_{c t}$ is the charge-transfer resistance, $R_{s}$ is the electrolyte resistance, $\omega$ is the angular frequency in the low frequency region, D is the diffusion coefficient, $\mathrm{R}$ is the gas constant, $\mathrm{T}$ is the absolute temperature, $\mathrm{F}$ is the Faraday's constant, $\mathrm{A}$ is the area of the electrode surface, and $\mathrm{C}$ is the molar concentration of $\mathrm{Li}^{+}$ions $\left(\mathrm{mol} \mathrm{cm}{ }^{-3}\right)$ [18-20]. The Y-PEDOT:PSS cathode material showed the highest lithium diffusion coefficient among the three samples. It is considered that the cause of low lithium diffusion coefficient is due to many oxidation products.

Fig. 6(a) shows the cycling performance and rate capability of the bare, Y-doped, and Y-PEDOT:PSS electrodes at room temperature. Although the cell based on $\mathrm{LiNi}_{0.8} \mathrm{Co} 0.1 \mathrm{Mn}_{0.1} \mathrm{O}_{2}$ retained only $63.7 \%$ of its initial capacity after 50 cycles, the Y-doped and Y-PEDOT:PSS electrodes showed capacity retention 


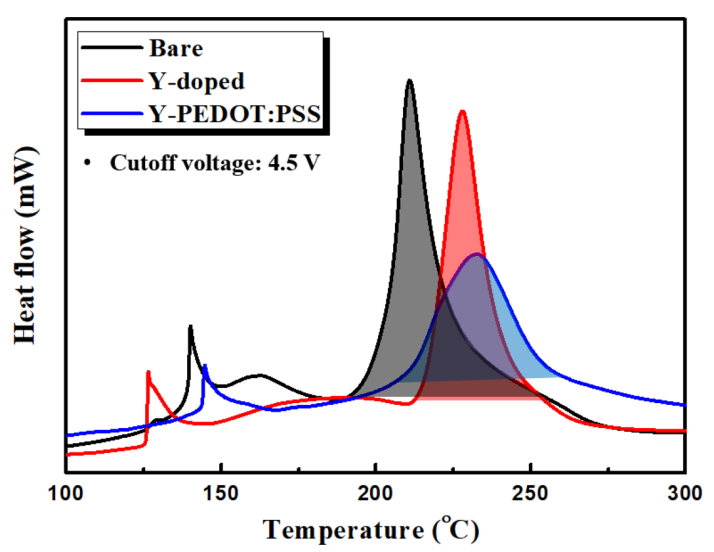

Fig. 7. DSC traces of the bare, Y-doped, and YPEDOT:PSS cathode materials charged to $4.5 \mathrm{~V}$.

of 80.7 and $86.7 \%$, respectively, at room temperature. Hence, yttrium doping stabilizes the lattice structure, and PEDOT:PSS coating suppresses the side reaction with the electrolyte and reduces the charge-transfer resistance, indicating excellent cycle characteristics.

Rate capability is one of the most important electrochemical characteristics of Li-ion batteries for electric and hybrid electric vehicles. Fig. 6(b) show that the Y-PEDOT:PSS electrode exhibited higher capacity than the bare and Y-doped electrodes at all C-rate, which further demonstrates the enhanced rate capability. The Y-doped cathode materials suggest that the pathway for $\mathrm{Li}+$ to intercalate/deintercalate had been expanded, which likely occurred because the $\mathrm{Y}-\mathrm{O}$ bond energy is considerably stronger than the $\mathrm{Ni}-\mathrm{O}$ bond energy [21].

Fig. 7 shows the DSC profiles of the bare, Y-doped, and Y-PEDOT:PSS cathode materials charged to $4.5 \mathrm{~V}$ in the presence of a $1 \mathrm{M} \mathrm{LiPF}_{6} / \mathrm{EC}: \mathrm{DEC}$ electrolyte. For the bare material, the onset temperature of the exothermic reaction peak is $210.8^{\circ} \mathrm{C}$. In contrast, the Ydoped and Y-PEDOT:PSS materials show higher onset temperatures and reduced heat generation compared to the bare cathode material. The high thermal stability of Y-PEDOT:PSS suggests that oxygen elution was suppressed due to the high binding energy between $\mathrm{Y}$ and oxygen, and the PEDOT:PSS coating layer effectively suppressed the exothermic reaction.

\section{Conclusions}

Yttrium doping and PEDOT:PSS coating display different effects on the structure and electrochemical properties of $\mathrm{LiNi}_{0.8} \mathrm{Co}_{0.1} \mathrm{Mn}_{0.1} \mathrm{O}_{2}$ cathode materials. Although both doping and coating improve the cycling stability of the $\mathrm{LiNi}_{0.8} \mathrm{Co}_{0.1} \mathrm{Mn}_{0.1} \mathrm{O}_{2}$ cathode material, the underlying mechanism of improvement is different. Suppression of lattice changes, i.e., improvement of structure stability during cycling, is attributed to the improved cycling stability of doped materials. The improvement of interface stability of coated materials during cycling is ascribed to the enhanced cycling stability of the coated materials. Combination of the two modification techniques may be a promising strategy to improve the cycling performance of cathode materials.

\section{Acknowledgement}

This study was supported by the granted financial resource from the Ministry of SMEs and Startups, Republic of Korea (S2928638) and the National Research Foundation of Korea (NRF) funded by the Korea government (MSIT, No. 2019R1F1A1057220) and by the Technology Innovation Program (or Industrial Strategic Technology Development Program-Material Parts Technology Development Project) (20003747, Development of highperformance cathode material manufacturing technology through valuable metal upcycling from waste battery and waste cathode material) funded by the Ministry of Trade, Industry \& Energy (MOTIE, Korea) and the Korea Agency for Infrastructure Technology.

\section{References}

[1] B. C. Jang and J. T. Son, J. Nanosci. Nanotechnol., 2016, 16(10), 10698-10701.

[2] Y. G. Ptushinskii, Low Temp. Phys., 2004, 30(1), 1-26.

[3] J. W. Shin and J. T. Son, J. New Mater. Electrochem. Syst., 2018, 21(2), 71-75.

[4] Y. Wen, B. Wang, G. Zeng, K. Nogita, D.Ye and L. Wang, Chem Asian J., 2015, 10(3), 661-666.

[5] S. Komaba, N. Yabuuchi, T. Nakayama, A. Ogata, T. Ishikawa and I. Nakai, Inorg. Chem., 2012, 51(11), 6211-6220.

[6] H. Li, G. Chen, B. Zhang, J. Xiu, Solid Sate Commun., 2008, 146(3-4), 115-120.

[7] P.-Y. Liao, J.-G. Duh, H.-S. Sheu, J. Power Sources., 2008, 183(2), 766-770.

[8] C.Q. Xu, Y.W. Tian, Y.C. Zhai, L.Y. Liu, Mater. Chem. Phys., 2006, 98(2-3), 532-538. 
[9] G.V. Subba Rao, B.V.R. Chowdari, H.J. Lindner, J. Power Sources., 2001, 97, 313-315.

[10] S. H. Ju, I. S. Kang, Y. S. Lee, W. K. Shin, S. Kim, K. Shin and D. W. Kim, ACS Appl Mater. \& Interfaces, 2014, 6(4), 2546-2552.

[11] D. Lepage, C. Michot, G. Liang, M. Gauthier, Schougaard and S. B. Angew, Chem. Int. Ed., 2011, $50(30), 6884$.

[12] L. Zhan, Z. Song, J. Zhang, J. Tang, H. Zhan, Y. Zhou and C. Zhan, Electrochim. Acta., 2008, 53(28), 83198323.

[13] Y. S. Lee, K. S. Lee, Y. K. Sun, Y. M. Lee and D. W. Kim, J. Power Sources., 2011, 196(16), 6997-7001.

[14] R.V. Mangalaraja, J. Mouzon, P. Hedstrom, I. Kero, K.V.S. Ramam, C.P. Camurri, M. Oden, J. Mater. Process. Technol., 2008, 208(1-3), 415-422.
[15] J.A. Dean, Lange's Handbook of Chemistry, fifteenth ed., 1999.

[16] J.R. Reimers, E. Rossen, C.D. Jones, J.R. Dahn, Solid State Ionics., 1993, 61(4), 335-344.

[17] M.D. Levi, G. Salitra, B. Markovsky, H. Teller, D. Aurback, U. Heider, L. Heider, J. Electrochem, Soc, 1999, 146, 1279

[18] G.Q. Liu, H.T. Kuo, R.S. Liu, C.H. Shen, D.S. Shy, X.K. Xing, J.M. Chen, J. Alloys Compd., 2010, 496(1-2), 512516.

[19] Q. Cao, H.P. Zhang, G.J. Wang, Q. Xia, Y.P. Wu, H.Q. Wu, Electrochem. Commun., 2007, 9(5), 1228-1232.

[20] A.J. Bard, L.R. Faulkner, Electrochemical Methods., 2001.

[21] G.-W. Yoo, T.-J. Park, J.-T. Son, J. New Mater. Electrochem. Syst., 2015, 18(1), 009-016. 